\section{Los Alamos}

NAT IONAL L AB OR AT OR Y

memorandum

QUALITY AND PLANNING

Los Alamos, New Mexico 87545 find report
$\angle A-54 B--96-43$

ToMs: Jim Porter, QP, MS M722 LE

From/MS: Lawrie Eaton/Dave Mason, QP, MS M722

Phone/FAX: 7--4434/5-6837

Symbol: QP/LP:96-004

Date: February 20, 1997

\title{
SUBJECT: Event Mapping Meeting
}

Dave Mason and I met on September 26 for an all-day meeting to evaluate how the strategic lab workshops would tie to this year's tactical planning exercise. In particular, we wanted to find recent events that would support the tactical goal decisions of the Lab, and we wanted to find events that verify the Lab's present course.

This report summarizes our findings. This information was also used as a data set for input into the FY96-97 Tactical Planning exercise that was held on January 22 and 23. The strategic planning work that NCRI has done is an important component to the near term tactical goals of the Lab.

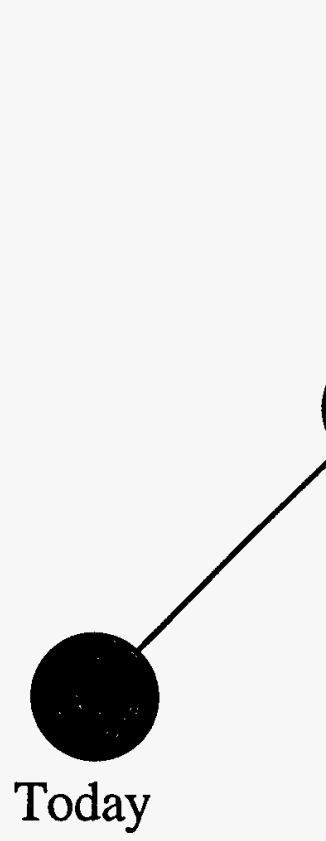

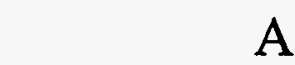

A

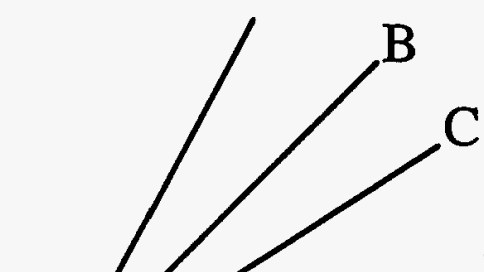

D

E

$10+$ years
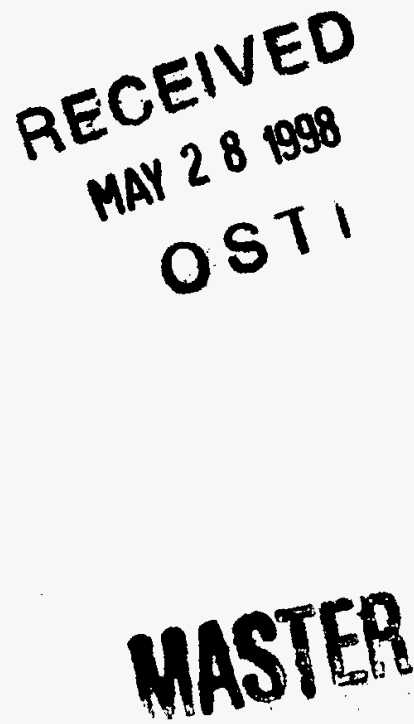

This drawing depicts an image of what the prior workshops concluded. Therefore, Dave and I were seeking events that were consistent with (or contrary to) this image; keep in mind that most of the events that have occurred are in the 0-10 year time frame, not 10-20.

Here is a list of what we picked out as interesting and supportive of a path that starts with the RND mission and eventually moves to something like endstate A. 


\section{DISCLAIMER}

This report was prepared as an account of work sponsored by an agency of the United States Government. Neither the United States Government nor any agency thereof, nor any of their employees, makes any warranty, express or implied, or assumes any legal liability or responsibility for the accuracy, completeness, or usefulness of any information, apparatus, product, or process disclosed, or represents that its use would not infringe privately owned rights. Reference herein to any specific commercial product, process, or service by trade name, trademark, manufacturer, or otherwise does not necessarily constitute or imply its endorsement, recommendation, or favoring by the United States Government or any agency thereof. The views and opinions of authors expressed herein do not necessarily state or reflect those of the United States Government or any agency thereof. 
Regarding endstate A, the military lab, a few comments are worth making. It was written to describe a military lab with a very broad mission. There is, however, a narrow interpretation of it that describes a Lab focused on the re-positioning, draw down, cleanup and proliferation issues surrounding the nuclear stockpile as the nation moves towards a preference for advanced conventional weapons. It is an aggressive peace mission. It has a compelling social need behind it. It is politically and socially acceptable. It could be the end of the Faustian Bargain. The Lab may be smaller, narrower in focus and may even miss some great science opportunities. But there is a way through the psychological burdens of the past work. In general, the prior workshops acknowledged endstate $\mathrm{A}$ as likely but they did not like the more aggressive military angle of the endstate. However, describing it as Reducing the Nuclear Danger, managing the "sunset issues" of the waste stream, getting serious about counter and non-proliferation work, etc., are all worthy goals of LANL staff. They see the work as so massive that they cannot see anything behind the work straight ahead for LANL. The events that have unfolded in the past 6-9 months support this view.

What this suggests for our work going forward is to set aside ABCDE as written and accept as the Lab endstate the nearer term (0-10 yrs) view resulting from Galvin. A review of events reveals this to be a reasonable idea. This also provides a fountain for linking the Tactical Plan to the Strategic Plan. It suggests we use some of the tactics as the topics to the short Future Mapping efforts we discussed for FY96.

\section{Galvin Commission Recommends Consolidating DOE Defense Labs, 1995.}

Yes, this was recommended by the Commission but the President decided not to consolidate the Labs. This was part of the A scenario AND it also would have greatly strengthened LANL's hand in the RND (Reducing the Nuclear Danger) mission. The fact that the President decided to keep three labs is NEGATIVE for LANL but it's impact is minimal.

\section{Congressional Subcommittee Staff Force Budget Cuts and Consolidation, 1995}

This did not happen in 1995 and, coupled with the President's decision to keep three labs, makes consolidation a moot point. See others comments about the Galvin event.

\section{$28 \%$ of DOE/DP Budget Held Back Pending Completion of a Clear 5yr Plan for Nukes, 1995}

This did not happen in 1995, though it could in out years. The event was not associated with any endstate.

Not clear if any action is required. Was this just an idle threat? Has such a plan been developed and agreed to? 
QP/LP:96-004

\section{DoD and DOE Focus on Dual Use, 1995}

This continues to be policy. It is associated with the RND mission as well as endstate A. It is positive for both. Dual use supports the 0-10 year strategy of combined military and civilian work. It also creates a far more complex proliferation problem to be managed.

Action required: Ensure that proliferation related work responds to the increasing threat caused by this policy?

\section{LANL Work Includes Weapons Rebuilds, 1995}

This was a highly likely event associated with endstate A. It has happened, although a semantic argument may continue for a while.

Action: The repercussion of acknowledging rebuilds should be reviewed in the context of developing a position on limited "production" at the LANL site. The big concern was the potential for a large, negative, impact on the science side of the organization.

\section{LANL Chosen by DOE to Develop and Test Advanced Remediation Techniques, 1995}

This has not happened yet but activity is pushing in this direction. It is associated with the RND mission, the A endstate, and to some extent a nuclear version of the B endstate. It is positive for all.

Action: LANL must push hard to see this happens at LANL versus somewhere else. It appears that Lockheed/Martin is preparing to be very aggressive on this front. While LANL says the right words, the culture of LANL treats this work as second class.

\section{AGEX/DARHT Project is Stopped by Suits from Environmental Activities, 1996}

This has happened. It is negative for both the RND mission and was considered a "must not" event for endstate A. It is not clear to NCRI what the real impact of this is and the Lab seems conflicted over its significant as well.

\section{Non-Proliferation Treaty Renewed, 1996}

This has happened. It is positively associated with the RND mission and the A endstate.

Action: Improved compliance monitoring?

US Complies with Comprehensive Test Ban Treaty, 1996

This has happened. The President has, with the support of the Labs, banned all future testing. It is positively associated with the RND mission and the A endstate.

Action: Improved compliance monitoring? 
Jim Porter

$-4$

February 20, 1996

QP/LP:96-004

\section{Capability Based Deterrence Policy Put Into Place, 1998}

This has not happened yet but activity appears to be pushing the US in this direction. It supports the SBSS portion of the RND mission. It was associated with both the A and C endstates.

\section{Stockpile Shrinks to Approximately 2000 Weapons, 2005}

This has not happened yet but activity appears to be pushing the US in this direction. It was associated with the $\mathrm{A}$ endstate and was viewed as highly likely.

\section{DOE Weapons Labs Re-chartered as True National Labs, 1996}

It is now clear that all the movement is in the opposite direction. "Get smaller and focus on your core mission" is the watch word in all government. This was associated with endstates C and $\mathrm{E}$; it was considered highly unlikely.

Action: Pushes the Lab to minimize anything viewed as outside the core RND mission. Pushes the Lab into endstate $\mathrm{A}$.

\section{DOE Terminates All Nuclear Weapons Testing Support, 1996}

This event has happened. It pushes the Lab towards SBSS and the RND mission.

\section{Industrial Projects at LANL Up 20\% from Previous Year, 1997}

It now appears that this is extremely unlikely. This further pushes the Lab into the core mission and, longer term, into endstate $\mathrm{A}$.

\section{NIST-ATP Program Becomes an Interagency Process..., 1997}

NIST and ATP are both caught up in the budget crunch and a Congressional debate about the need for DoC. It now appears that ATP will never get off the ground. This further pushes the Lab into the core mission and, longer term, into endstate A.

DOE Warns that Spent Commercial Reactor Fuel is a Major Proliferation Threat, 1998

This has been acknowledged, though quietly, by DOE. It further pushes the Lab into the core mission and, longer term, into endstate A. It highlights the need to expand work related to proliferation threats.

Non-Lethal Weapons Work Helps to Reshape LANL Image, 1998

The Lab is getting unusually large amounts of press coverage on this area. Its impact on the public's image of the Lab is not clear. 


\section{Global Warming Theory Proven, 2005}

In fact, news suggests this is now proven fact. It would/could drive the Lab towards endatate $B$ if anyone wanted to do anything about it but such a response seems unlikely.

\section{Overall US Spending on Science Has Been Flat or Decreasing for Three Years, 1998}

The budget appears to be putting this trend in place. It will limit LANL's ability to diversify its work and funding sources.

\section{Economic Role of LANL in Northern New Mexico Declines, 2005}

The RIF appears to be making this a fact.

\section{$\mathrm{LE} / \mathrm{DM} / \mathrm{mm}$}

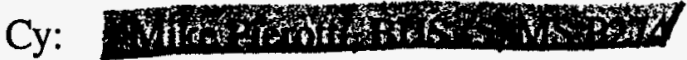 \\ Rich Bastian, QP, MS M722 \\ Bill Wadt, QP, MS M722 \\ Mary Trainor, QP, MS M722 \\ Rita Spencer, QP, MS M722 \\ QP File}




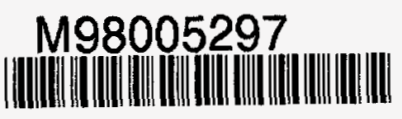

Report Number (14) LA-SUB $--96-43$

Publ. Date (11) 19970220 Sponsor Code (18) DOE/HR, XF UC Category (19) UC-900, DOE/ER 